\title{
Correction to: Type 2 Diabetes Mellitus and Preoperative HbA1c Level Have no Consequence on Outcomes after Laparoscopic Sleeve Gastrectomy-a Cohort Study
}

\author{
Michał Wysocki ${ }^{1,2} \cdot$ Maciej Walędziak $^{3} \cdot$ Hady Razak Hady $^{4} \cdot$ Mikołaj Czerniawski $^{4} \cdot$ Monika Proczko-Stepaniak $^{5}$. \\ Michał Szymański ${ }^{5}$ - Natalia Dowgiałło-Wnukiewicz ${ }^{6}$ Piotr Kozera ${ }^{6}$ - Jacek Szeliga ${ }^{7}$ - Michał Orłowski ${ }^{8}$. \\ Michał Pędziwiatr $^{1,2}$ - Magdalena Szopa ${ }^{9}$ - Andrzej Budzyński ${ }^{1,2}$ • Piotr Major ${ }^{1,2}$ (D)
}

\section{Correction to: Obesity Surgery https://doi.org/10.1007/s11695-019-03936-y}

Some of the author affiliations were incorrectly assigned in the original article. They are correct here.

The online version of the original article can be found at https://doi.org/ 10.1007/s11695-019-03936-y

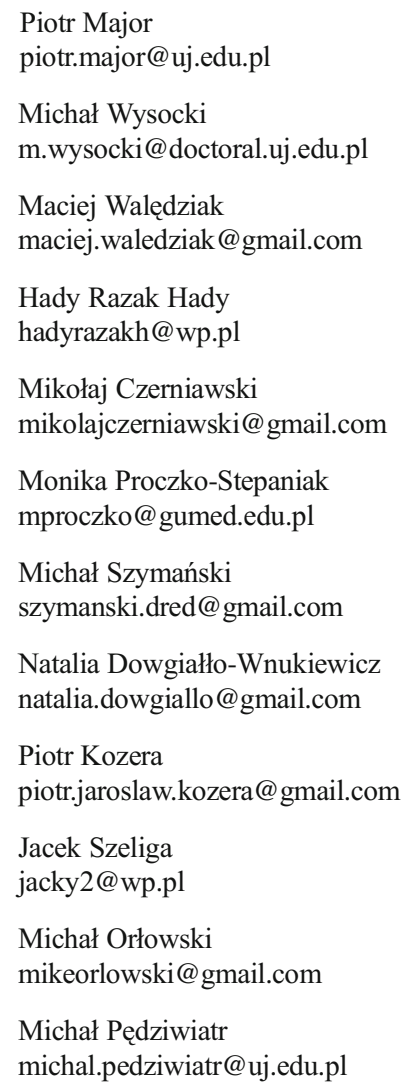

Pulisher's Note Springer Nature remains neutral with regard to jurisdictional claims in published maps and institutional affiliations
Magdalena Szopa

magdalena.szopa@uj.edu.pl

Andrzej Budzyński

andrzej.budzynski@uj.edu.pl

1 2nd Department of General Surgery, Jagiellonian University Medical College, Kraków, Poland

2 Training and Innovation in Surgery (CERTAIN Surgery), Centre for Research, Krakow, Poland

3 Department of General, Oncological, Metabolic and Thoracic Surgery, Military Institute of Medicine, Warsaw, Poland

4 First Clinical Department of General and Endocrine Surgery, Medical University of Bialystok, Bialystok, Poland

5 Department of General, Endocrine and Transplant Surgery, Medical University of Gdansk, Gdansk, Poland

6 Chair and Clinic of General, Minimally Invasive and Elderly Surgery, University of Warmia \& Mazury, Olsztyn, Poland

7 Department of General, Gastroenterological, and Oncological Surgery Collegium Medicum, Nicolaus Copernicus University, Torun, Poland

8 General and Vascular Surgery Department, Ceynowa Hospital, Wejherowo, Poland

9 Department of Metabolic Diseases, Jagiellonian University Medical College, Krakow, Poland 